University of Nebraska - Lincoln

DigitalCommons@University of Nebraska - Lincoln

2012

\title{
Structure and magnetic properties of Co-W clusters produced by inert gas condensation
}

\author{
Farhad Reza Golkar-Fard \\ University of Nebraska-Lincoln, farhad518@huskers.unl.edu \\ Matthew J. Kramer \\ Ames Laboratory, USDOE, mjkramer@ameslab.gov \\ Y. Zhang \\ Ames Laboratory \\ R. W. McCallum \\ Ames Laboratory \\ Ralph Skomski \\ University of Nebraska-Lincoln, rskomski2@unl.edu \\ See next page for additional authors
}

Follow this and additional works at: https://digitalcommons.unl.edu/physicssellmyer

Part of the Physics Commons

Golkar-Fard, Farhad Reza; Kramer, Matthew J.; Zhang, Y.; McCallum, R. W.; Skomski, Ralph; Sellmyer, David J.; and Shield, Jeffrey E., "Structure and magnetic properties of Co-W clusters produced by inert gas condensation" (2012). David Sellmyer Publications. 230.

https://digitalcommons.unl.edu/physicssellmyer/230

This Article is brought to you for free and open access by the Research Papers in Physics and Astronomy at DigitalCommons@University of Nebraska - Lincoln. It has been accepted for inclusion in David Sellmyer Publications by an authorized administrator of DigitalCommons@University of Nebraska - Lincoln. 


\section{Authors}

Farhad Reza Golkar-Fard, Matthew J. Kramer, Y. Zhang, R. W. McCallum, Ralph Skomski, David J. Sellmyer, and Jeffrey E. Shield 


\title{
Structure and magnetic properties of Co-W clusters produced by inert gas condensation
}

\author{
Farhad Golkar, ${ }^{1, \text { a) }}$ M. J. Kramer, ${ }^{2}$ Y. Zhang, ${ }^{2}$ R. W. McCallum, ${ }^{2}$ R. Skomski, ${ }^{3,4}$ \\ D. J. Sellmyer, ${ }^{3,4}$ and J. E. Shield ${ }^{1,4}$ \\ ${ }^{1}$ Mechanical and Materials Engineering, University of Nebraska, Lincoln, Nebraska 68588, USA \\ ${ }^{2}$ Ames Laboratory, Ames, Iowa 50011, USA \\ ${ }^{3}$ Physics and Astronomy, University of Nebraska, Lincoln, Nebraska 68588, USA \\ ${ }^{4}$ Nebraska Center for Materials and Nanoscience, University of Nebraska, Lincoln, Nebraska 68588, USA
}

(Presented 2 November 2011; received 23 September 2011; accepted 10 November 2011; published online 6 March 2012)

\begin{abstract}
In this article, inert-gas condensation was used to synthesize Co-W clusters. The formation, structure, and magnetic properties of the clusters were investigated. Sub-10-nm clusters were obtained, and the structures and average sizes were strongly dependent on sputtering power. At low sputtering powers, the clusters were predominantly amorphous, while, at high sputtering power, the clusters were crystalline. $\mathrm{X}$ ray diffraction and transmission electron microscopy revealed clusters with hcp structure at high sputtering power. The magnetic properties were dependent on the sputtering power and temperature, with the highest coercivity of $810 \mathrm{Oe}$ at $10 \mathrm{~K}$ for high sputtering power. (C) 2012 American Institute of Physics. [doi:10.1063/1.3676425]
\end{abstract}

\section{INTRODUCTION}

With increasing world-wide demand on the rare earth elements for electronics and permanent magnet applications, such as wind turbines, hybrid/electric vehicles, hard disk drives, and medical imaging, there is renewed focus on developing permanent magnet alloys with reduced or no rare-earth content. Co in the hexagonal close-packed structure has a moderate degree of magnetocrystalline anisotropy $\left(\mathrm{K}_{\mathrm{u}} \sim 4.5(10)^{6} \mathrm{ergs} / \mathrm{cm}^{3}\right)$, but is too low for permanent magnet applications. Recent calculations show that dissolving $5 \mathrm{~d}$ transition metals into $\mathrm{Co}$ or $\mathrm{Fe}$ induces an increase in magnetocrystalline anisotropy. ${ }^{1}$ However, in general, the solubility of $5 \mathrm{~d}$ transition metals into $\mathrm{Fe}$ or $\mathrm{Co}$ is limited. Nonequilibrium processing can extend solubility beyond equilibrium limits. Specifically, cluster formation via inert-gas condensation can produce non-equilibrium solid solutions. ${ }^{2,3}$ However, the cluster structure formation has been found to be critically dependent on processing conditions, notably the sputtering power when dc magnetron sputtering is used to create the gas phase, ${ }^{4-6}$ and the structure formation is also cluster size-dependent. ${ }^{7}$ Here, we report the formation, structure, and magnetic properties of $\mathrm{Co}-\mathrm{W}$ clusters using inert gas condensation.

\section{EXPERIMENTS}

Co-W alloy clusters were prepared by using inert-gas condensation (IGC). ${ }^{8}$ DC magnetron sputtering was used to form the atomic gas and a Co-W composite target, consisting of $\mathrm{W}$ plugs inserted in a Co target. Clusters were produced using two different sputtering powers: $50 \mathrm{~W}$ and $150 \mathrm{~W}$. In this experiment, the cluster-forming chamber was cooled by water to maintain a temperature of approximately $18^{\circ} \mathrm{C}$.

\footnotetext{
a) Author to whom correspondence should be addressed. Electronic mail: farhad518@huskers.unl.edu.
}

The composition of the Co-W nanoclusters was set by using $\mathrm{W}$ plugs inserted in the Co target. For this study, W plugs comprising approximately $16 \%$ of the "racetrack" typical of magnetron sputtering were employed, which, according to typical sputtering yields, would result in a composition of approximately 92 at. $\%$ Co and 8 at. $\% \mathrm{~W}$. For magnetic measurements, the $\mathrm{Co}-\mathrm{W}$ clusters were imbedded in a $\mathrm{C}$ matrix by alternate deposition from the cluster source and an RF source positioned perpendicular to the cluster source. Overall thickness of the composite films, which were deposited on $\mathrm{Si}$ substrate, was approximately $30 \mathrm{~nm}$. The magnetic measurements were conducted at $10 \mathrm{~K}$ and $300 \mathrm{~K}$ using a Quantum Design magnetic property measurement system (MPMS) superconducting quantum interference device (SQUID) magnetometer. The sample signal was determined by subtracting a diamagnetic contribution from the Si substrate.

For characterization using transmission electron microscopy (TEM), the Co-W clusters were deposited directly onto graphite support films, and to prevent oxidation, a thin layer of $\mathrm{C}$ was deposited after cluster deposition. TEM was accomplished using a JEOL 2010 operating at $200 \mathrm{kV}$ and a FEI Tecnai $\mathrm{G}^{2} \mathrm{~F} 20$ operating at $200 \mathrm{kV}$. The compositions of the clusters were determined by energy dispersive $\mathrm{x}$ ray spectroscopy (EDS) operating in the scanning TEM (STEM) mode. Area scans encompassing a number of clusters were used to obtain an average composition. For phase characterization, the Rigaku Multiflex $\mathrm{x}$ ray diffractometer (XRD) with $\mathrm{Cu} \mathrm{K} \alpha$ radiation was used. Cluster films approximately $30 \mathrm{~nm}$ thick were deposited for $\mathrm{x}$ ray diffraction studies.

\section{RESULTS AND DISCUSSION}

TEM images of the as-deposited clusters revealed sub10-nm clusters for both deposition conditions (Fig. 1). Analysis of the size distribution from the TEM micrographs 


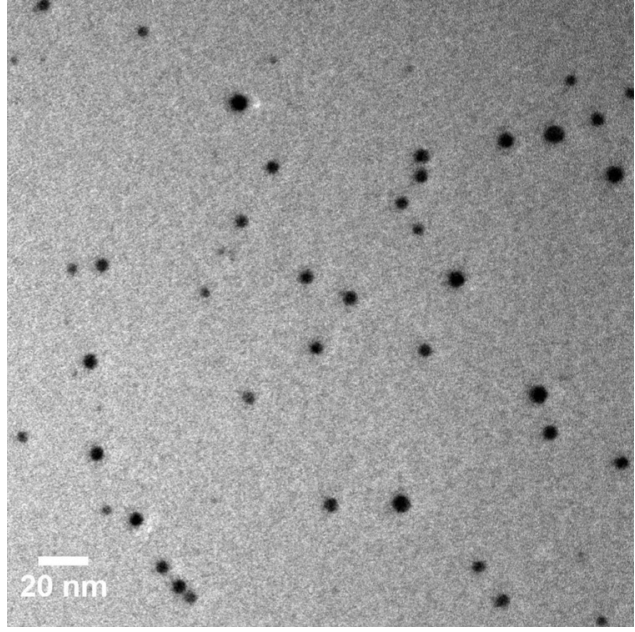

FIG. 1. TEM image of Co-W clusters produced with magnetron sputter power of $50 \mathrm{~W}$, showing the particle sizes below $10 \mathrm{~nm}$.

revealed that clusters increased in average size from $5.7 \pm 1.8 \mathrm{~nm}$ to $7.7 \pm 2.7 \mathrm{~nm}$ when increasing the sputtering power from $50 \mathrm{~W}$ to $150 \mathrm{~W}$. EDS analysis of data collected using scanning mode on different areas revealed a consistent composition of approximately 95 at. $\%$ of Co and 5 at. $\% \mathrm{~W}$ for both sputtering powers. This composition lies in the twophase hcp $\mathrm{Co}+\mathrm{Co}_{3} \mathrm{~W}$ phase field in the equilibrium phase diagram. ${ }^{9}$ Also, EDS analysis performed on the background revealed a W-rich composition with low Co content. However, the signal was quite low, and further work is necessary to determine if a second, W-rich phase forms during cluster deposition.

Figure 2 shows the $\mathrm{x}$ ray data for the two sputtering powers. For the $50 \mathrm{~W}$ sample, the $\mathrm{x}$ ray diffraction pattern shows a broad diffraction maxima centered at $2 \theta \sim 44^{\circ}$. For the $150 \mathrm{~W}$ sample, the $\mathrm{x}$ ray diffraction data revealed a number of broad diffraction peaks consistent with hcp Co peaks. However, peaks corresponding to the $\mathrm{Co}_{3} \mathrm{~W}$ phase are also close to the observed peaks. Other peaks associated with $\mathrm{Co}_{3} \mathrm{~W}$ are absent, but this may be due to their low intensity.

High-resolution TEM (HRTEM) images of the asdeposited samples show that, at low sputtering power, clusters were predominantly amorphous, although some lattice fringes were evident in some clusters. The selected-area electron-diffraction (SAD) patterns at low sputtering power

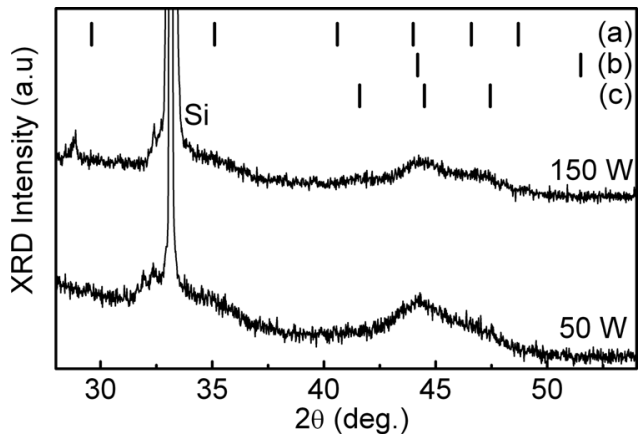

FIG. 2. X ray diffraction pattern for both sputtering powers. The standard diffraction lines for (a) $\mathrm{Co}_{3} \mathrm{~W}$, (b) fcc Co, and (c) hcp Co are presented as vertical lines. showed diffused rings together with a few sharp diffraction spots, revealing that the samples were predominantly amorphous. At high sputtering power, lattice fringes were readily observed, indicating an increased degree of crystallinity (Fig. 3). The lattice fringes were observed to extend across the cluster diameter, indicating that the clusters are single crystalline. The fast-Fourier transform (FFT) of Fig. 3 is shown in the inset; this was indexed to the [0001] zone axis of the hcp Co structure. FFTs of clusters in other orientations were indexed to different zone axes, corresponding to the hcp Co structure. The SAD patterns were indexed to a hcp Co structure with lattice parameters $\mathrm{a} \sim 0.262$ and $\mathrm{c} \sim 0.408 \mathrm{~nm}$, close to literature values. However, high-angle annular dark field STEM (HAADF) images of larger ( $>12 \mathrm{~nm}$ ) single-crystalline clusters showed internal compositional variations, suggesting the co-existence of both hcp $\mathrm{Co}$ and $\mathrm{Co}_{3} \mathrm{~W}$, and HRTEM images of smaller clusters indicated the presence of fcc Co. ${ }^{10}$

The magnetic properties of the composite were measured at 10 and $300 \mathrm{~K}$ (Fig. 4). The properties were dependent on the sputtering power (and thus degree of crystallinity) and temperature. Clusters formed at a higher power had a higher coercivity at both $10 \mathrm{~K}$ and $300 \mathrm{~K}$. At $10 \mathrm{~K}$, the coercivity increased from $540 \mathrm{Oe}$ at $50 \mathrm{~W}$ to $810 \mathrm{Oe}$ at $150 \mathrm{~W}$. The remanence ratio, $\mathrm{M}_{\mathrm{r}} / \mathrm{M}_{\mathrm{s}}$, remained the same, about 0.5 , regardless of sputtering power. At $300 \mathrm{~K}$, coercivity values were $23 \mathrm{Oe}$ and $130 \mathrm{Oe}$ at $50 \mathrm{~W}$ and $150 \mathrm{~W}$, respectively. The remanence ratio also increased from approximately 0.06 for low sputtering power to 0.2 for high sputtering power. The low coercivities observed for clusters formed at $50 \mathrm{~W}$ were due to the predominantly amorphous structure. However, hcp $\mathrm{Co}$, the structure formed at $150 \mathrm{~W}$, typically is associated with a higher coercivity. The low observed coercivity may be due to a lower anisotropy for the Co-W solid solution. Additionally, the clusters may contain other structures, such as fcc Co, with lower magnetocrystalline anisotropy, which have been reported by Yamamuro et al. ${ }^{7}$ for Co clusters in the $6-13 \mathrm{~nm}$ size range.

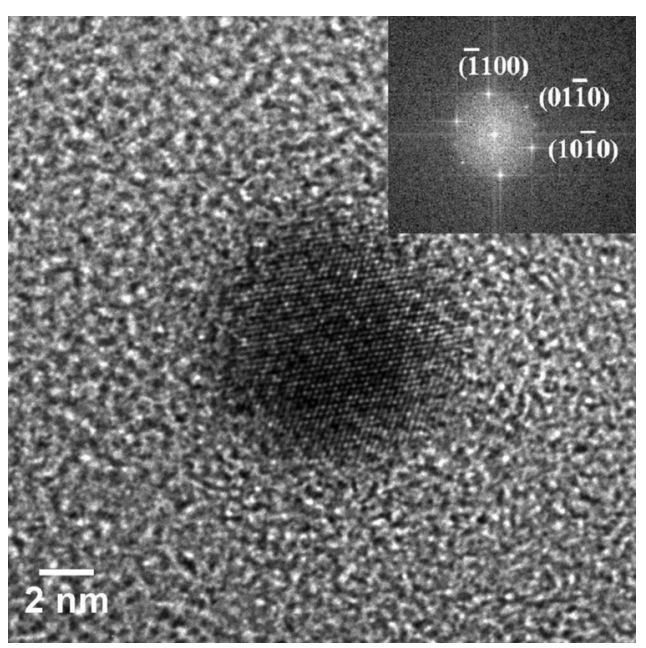

FIG. 3. High-resolution TEM image of individual Co-W cluster. (Inset) Fast Fourier transform of the HRTEM image shows the diffraction spots corresponding to the [0001] zone axis of the hcp structure. 

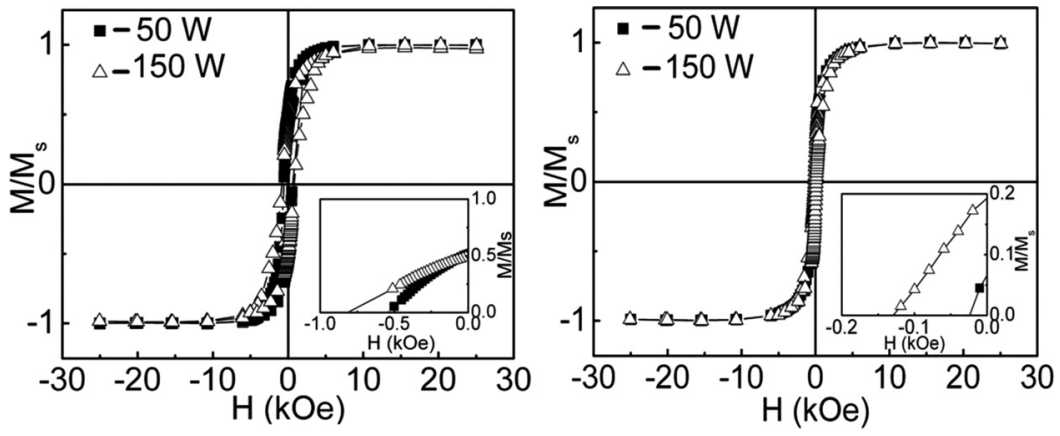

FIG. 4. Hysteresis measurements of Co-W clusters obtained at (left) $10 \mathrm{~K}$ and (right) $300 \mathrm{~K}$. The inset shows second quadrants.

\section{CONCLUSION}

In this work, inert gas condensation was used to synthesize Co-W alloy clusters. Clusters with sizes of $5.7 \pm 1.8 \mathrm{~nm}$ and $7.7 \pm 2.7 \mathrm{~nm}$ were formed at sputtering powers of $50 \mathrm{~W}$ and $150 \mathrm{~W}$, respectively. $\mathrm{X}$ ray diffraction and TEM results showed that the structures formed at low power were predominantly amorphous, while higher sputtering power formed crystalline clusters with the hcp Co structure with $\mathrm{W}$ in solid solution. The $\mathrm{W}$ content was approximately 5 at. $\%$, above the negligible equilibrium solubility limit of $\mathrm{W}$ in hcp Co. The crystalline clusters were determined to have higher coercivity at both $10 \mathrm{~K}$ and $300 \mathrm{~K}$.

\section{ACKNOWLEDGMENTS}

This work was supported by the Department of EnergyEnergy Efficiency and Renewable Energy, Vehicles Technology Office, PEEM program under Contract No. DEAC02-07CH11358 for the operation of Ames Laboratory (USDOE) and Sub-contract No. SC-10-343 to the University of Nebraska-Lincoln.
${ }^{1}$ R. Skomski, V. Sharma, B. Balamurugan, J. E. Shield, A. Kashyap, and D. J. Sellmyer, Proceedings of the 21st International Workshop on Rare-Earth Permanent Magnets and Their Applications (REPM'10), Bled, Slovenia, 29 August-2 September 2010, edited by S. Kobe and P. McGuinness (Jozef Stefan Institute, Ljubljana, 2010), pp. 55-60.

${ }^{2}$ V. M. Koshkin and V. V. Slezov, Tech. Phys. Lett. 30, 367 (2004).

${ }^{3}$ P. Mukherjee, Y. Q. Wu, M. J. Kramer, and J. E. Shield, "Novel structural states in Fe-Au nanoclusters," (unpublished).

${ }^{4}$ B. Balasubramanian, R. Skomski, X. Li, S. Valloppilly, J. E. Shield, G. C. Hadjipanayis, and D. J. Sellmyer, Nano Lett. 11, 1747 (2011)

${ }^{5}$ M. M. Patterson, A. Cochran, J. Ferina, V. J. Litwinowicz, X. Rui, T. A. Zimmerman, Z. Sun, M. J. Kramer, D. J. Sellmyer, and J. E. Shield, J. Vac. Sci. Technol. B28, 273 (2010).

${ }^{6}$ J. M. Qiu and J. P. Wang, Appl. Phys. Lett. 88, 192505 (2006).

${ }^{7}$ S. Yamamuro, K. Sumiyama, T. J. Konno, K. Suzuki, Mater. Trans., JIM 40(12), 1450 (1999).

${ }^{8}$ H. Haberland, M. Karrais, M. Mall, and Y. Thurner, J. Vac. Sci. Technol. A 10, 3266 (1992).

${ }^{9}$ S. V. Nagender Naidu, A. M. Sriramamurthy, P. Rama Rao, in Binary Alloy Phase Diagrams, edited by H. Okamoto, P. R. Subramanian, L. Kacprzak (ASM International, Materials Park, OH, 1992), Vol. 2, p. 1257.

${ }^{10}$ M. J. Kramer, Y. Zhang, F. Golkar, R. W. McCallum, R. Skomski, D. J. Sellmyer, and J. E. Shield, "Structural studies of Co-W clusters produced by inert gas condensation," (unpublished). 